\title{
Revised models and genetic parameter estimates for production and reproduction traits in the Elsenburg Dormer sheep stud
}

\author{
J.B. van Wyk ${ }^{\# 1}$, M.D. Fair ${ }^{1}$ \& S.W.P. Cloete ${ }^{1,2}$ \\ ${ }^{1}$ Department of Animal-, Wildlife- and Grassland Sciences, University of the Free State, P.O. Box 339, Bloemfontein \\ 9301, South Africa \\ ${ }^{2}$ Elsenburg Agricultural Development Institute, Private Bag X1, Elsenburg 7607, South Africa
}

\begin{abstract}
Genetic parameters for production and reproduction traits in the Elsenburg Dormer sheep stud were estimated using records of 11743 lambs born between 1943 and 2002. An animal model with direct and maternal additive, maternal permanent and temporary environmental effects was fitted for traits considered traits of the lamb (birth and weaning weight and survival). Fixed effects were sex, birth status, year and age of dam. Weaning weights were pre-adjusted to a 100-day equivalent. For reproduction traits (considered as traits of the ewe), which included number and weight of lambs born and weaned, repeatability models were fitted. The random part consisted of direct additive and ewe and sire permanent environmental effects. Direct and maternal heritability estimates were 0.13 and 0.23 for birth weight and 0.07 and 0.09 for weaning weight. Corresponding proportions of total phenotypic variance due to maternal permanent and temporary environment were 0.09 and 0.28 and 0.06 and 0.22 respectively. The genetic correlation between animal effects was -0.23 in the case of birth weight. The results showed that temporary environment (full sibs within a year) generally has a major effect on all pre-weaning traits. The direct heritability estimate of survival was 0.02 while the temporary maternal environmental variance as a proportion of phenotypic variance was 0.10 . The estimates obtained for number and weight of lambs born and weaned were generally low, ranging from 0.03 for number of lambs born to 0.11 for total weight at birth. The permanent environmental effect of the ewe accounted for $6-7 \%$ of the total phenotypic variance. Genetic correlations of total weight of lamb weaned with the other reproduction traits were generally high (0.64 to 0.92$)$ with low standard errors. The corresponding phenotypic, environmental and ewe permanent environmental correlations were all medium to high and estimated with a fair deal of accuracy according to low standard errors. The genetic relationship between weaning weight of the ewe and her lifetime reproduction (accumulated over four lambing chances) ranged between 0.40 and 0.67. Correlations between number of lambs weaned per ewe and weight of lamb weaned per ewe were particularly high $(0.8-0.9)$. It was concluded that the maternal environmental effect should be partitioned into two components (permanent and temporary) when data sets involving multiple births over many generations are considered.
\end{abstract}

Keywords: Dormer sheep, genetic parameters, temporary and permanent environmental effects, early growth, survival and reproduction traits

${ }^{\#}$ Corresponding author. E-mail: vanwykjb.sci@mail.uovs.ac.za

\section{Introduction}

Sheep breeding enterprises have to be dynamic in implementing changes to meet the changing demands of consumers, changing environments and economic realities. Accurate genetic parameter estimates for a breed are needed before changes are made to selection criteria to meet ever changing needs. Continuing advances in computer technology, hard- and software, as well as improved statistical methods allow animal breeders to continually re-evaluate genetic parameters to better define selection strategies for the modern market.

The Elsenburg Dormer stud which also hailed the beginning of the Dormer sheep breed, was started at the Elsenburg College of Agriculture in 1940 by crossing Dorset Horn rams with German Merino ewes. The stud has been studied previously by Van der Merwe (1976) and Van Wyk et al. (1993a, b, c, d, e). Each study, although done on the same stud, is unique in the sense that more data were available each year. The methods of the analysis were also completely different due to vast improvements in methodology during the 17 years separating the first two studies. A further updated genetic analysis for the stud was considered important especially in view of improvements in methodology to fit additional random factors and of the inevitably increased inbreeding. Although inbreeding was taken into account in analyses it does not form part of this study but was partly documented by Van Wyk et al. (2002). Since reproduction is of vital 
importance in any sheep breeding enterprise another objective was, therefore, to estimate genetic parameters for reproduction traits not considered by Van Wyk et al. (1993a, b, c, d, e). Van der Merwe (1976) assessed aspects of reproduction but the methods used have become completely outdated.

\section{Materials and Methods}

Data were obtained from the Dormer sheep stud of the Elsenburg Agricultural Development Institute near Stellenbosch, comprising a flock of ca. 110-180 breeding ewes. The farm Elsenburg is situated in the Boland sub-region of the Winter Rainfall Region, about $50 \mathrm{~km}$ east of Cape Town and $10 \mathrm{~km}$ north of Stellenbosch at an altitude of approximately $177 \mathrm{~m}$ above sea level $\left(33^{\circ} 51^{\prime} \mathrm{S}, 18^{\circ} 30^{\prime} \mathrm{E}\right)$. The farm has an average annual predominantly winter (June - August) rainfall of $642 \mathrm{~mm}$. The average maximum (minimum) summer and winter temperatures are $25.4^{\circ} \mathrm{C}\left(12.6{ }^{\circ} \mathrm{C}\right)$ and $17.9^{\circ} \mathrm{C}\left(8.1{ }^{\circ} \mathrm{C}\right)$.

The Dormer sheep breed originated from a small number of animals (two first-cross rams and 77 first-cross ewe lambs). It can be assumed that, being a cross between two unrelated breeds (Dorset Horn $\mathrm{x}$ German Merino), the inbreeding coefficients of the base animals were zero. The stud was closed since its inception with all replacements coming from within. However, in 1997 three totally unrelated rams were introduced in an effort to lower the level of inbreeding

During the early stages selection emphasis was mainly on visually assessed conformation. In later years rams and ewes were selected on the reproduction performance and fecundity of their dams and high lamb growth. Additionally, replacements had to comply with the breed standards required for purebred Dormer registration. Sires were used for two consecutive years while ewes were not replaced after any specific time, but were culled for failure to lamb in subsequent seasons, excessive teeth wear or other abnormalities.

Flock management was designed to ensure uniform treatment as far as practically possible. Each ram was paddock-mated to 25-30 identified ewes. Limited cross-fostering of orphaned lambs apparently did take place and may have some effect on the validity of the data. This, however, is a universal problem in sheep breeding research and almost impossible to control effectively.

The data used were collected in the period 1941 to 2002. A total of 11743 birth weight and 9657 weaning weight records, the progeny of 301 sires and 2551 dams, was available after editing. In the data set used, $48.6 \%$ of the lambs were male and $51.4 \%$ were female. Singles, twins and triplets represented $34.5 \%$, $61 \%$ and $4.5 \%$ of the records respectively. According to Johnson \& Garrick (1990), crossbred performance records should be excluded or analysed as a separate contemporary group to remove the possible average effect of heterosis. Records of the two years 1941 and 1942 represent the progeny of the initial crosses and also, since sires were nested within these first two years, these records were excluded. A more detailed description of the genetic base (history), selection criteria and management of the stud is given by Van Wyk et al. (1993a).

The traits analysed can be assigned to two main categories: traits of the lamb and traits of the ewe: a) Lamb traits: birth weight within 24 hours of birth (BW); weaning weight (WW) adjusted to 100 days and lamb survival (whether a lamb was dead or alive at weaning). b) Ewe traits: total weight of lamb weaned (TWW) (the sum of naturally reared individual lamb weights within a year per ewe lambing); number of lambs born (NLB) (the total number of lambs born alive within a year per ewe lambing); number of lambs weaned (NLW) (the total number of lambs weaned within a year per ewe lambing).

A description of the data used in the analysis is presented in Table 1. All weaning weights were adjusted a priori to a 100-day equivalent. This was necessary since prior to 1970 records were adjusted to a 100-day equivalent before recording. Individual weaning weights were then corrected for the effects of sex and birth year, and used to calculate total weight of lamb weaned for a specific parity in individual ewes. Both corrected and uncorrected birth and weaning weights were used to calculate total weight of lamb born and weaned per ewe per year.

The fixed effects included in the model for lamb traits were year of birth (1943-2002), sex (males, females), type of birth (singles and multiples) and age of dam (2 - 7 years and older). For the ewe traits only year of birth of the lamb and age of dam was fitted as fixed effects. Total weight of lamb at birth and weaning was pre-adjusted (additive) for sex and year of birth of the lamb.

Statistical analyses were divided into two consecutive steps. Firstly, the significance of fixed effects was tested conducting least squares analyses of variance using the GLM procedure of SAS (1991). Effects found to be significant $(\mathrm{P}<0.05)$ in these analyses were retained in subsequent analyses. 
Table 1 Description of data used after editing for production and reproduction traits and survival (19432002) $(\mathrm{n}=$ number of records, $\mathrm{CV} \%=$ coefficient of variation $)$

\begin{tabular}{lcccc}
\hline \multicolumn{1}{c}{ Trait } & $\mathrm{n}$ & Mean & CV\% & Range \\
\hline Lamb traits & & & & \\
$\quad$ Birth weight (kg) & 11743 & 3.9 & 21.9 & $1.4-8.5$ \\
$\quad$ Weaning weight (kg) & 9657 & 29.0 & 21.9 & $9.8-51.5$ \\
$\quad$ Survival & 11721 & 0.82 & 46.3 & $0-1$ \\
Ewe traits & & & & \\
$\quad$ Total birth weight per parity (kg) & 7890 & 5.8 & 35.2 & $0-14.0$ \\
$\quad$ Uncorrected & 7890 & 6.8 & 34.6 & $0-15.9$ \\
$\quad$ Corrected & & & & \\
Total weaning weight per parity (kg) & 7890 & 35.4 & 49.0 & $0-98.4$ \\
$\quad$ Uncorrected & 7890 & 35.9 & 47.8 & $0-95.6$ \\
$\quad$ Corrected & \\
Number of lambs born per parity & 7890 & 1.49 & 36.2 & $1-4$ \\
$\quad$ Number of lambs weaned per parity & 7890 & 1.22 & 51.6 & $0-4$ \\
\hline
\end{tabular}

\# Total birth and weaning weight corrected for sex and year of birth

The second step was the estimation of (co)variance components for each trait. This was obtained using the ASREML program (Gilmour et al., 2002) fitting univariate animal models. The permanent environmental effect of the dam is equivalent to an environmental effect of maternal half sibs, which is permanent over the years. This, however, does not account for variation within a litter (full sibs within a year) (Maniatis \& Pollot, 2002). The partitioning of the maternal environmental effect into permanent and temporary environmental effects in this study was augmented by the fact that the average number of progeny records per dam was 4.4 and the average number of lambs born per parity was 1.5 lambs. Therefore, a temporary environmental effect was fitted for all lamb traits. Twelve general forms of mixed-models were fitted for lamb traits and three for ewe traits, and are presented below. Tests of significance of each random effect were performed using log likelihood ratio tests after including each random effect (excluding residual) to the fixed effects model. An effect was considered significant when its inclusion in the model caused a significant increase in the log likelihood. A chi square distribution for $\alpha=0.05$ and one degree of freedom was used as the critical test statistic (3.841). When -2 times the difference between log likelihoods was greater than the critical value the inclusion of the effect was considered significant. When differences between log likelihoods were not significant the model with the fewest random effects was chosen. The following univariate animal models (in matrix notation) were fitted for lamb traits:

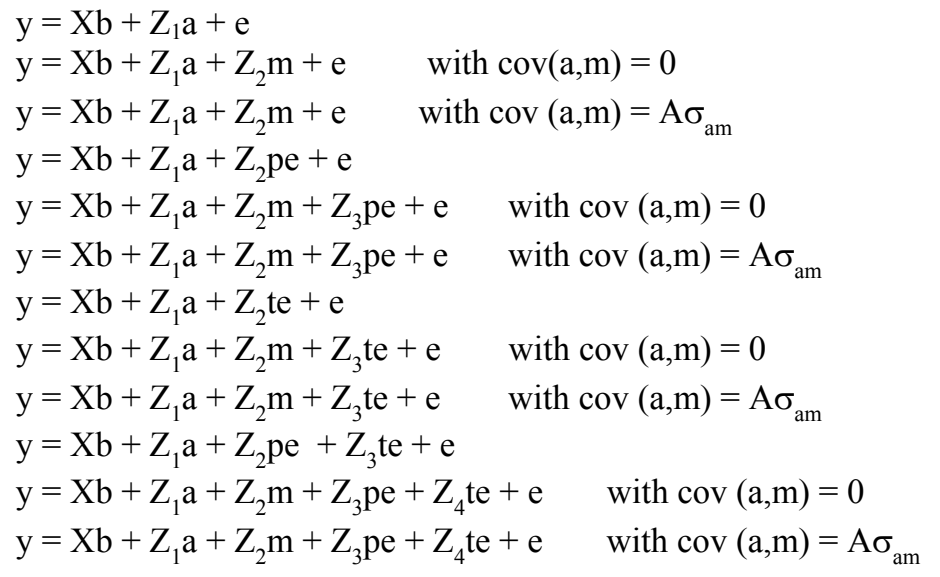

Similar procedures were followed when data recorded on ewes were considered except that a repeatability model was used. Permanent environmental effects due to the ewe and service sire effect were added to the direct additive effect resulting in the following three genetic models for analyses:

$\mathrm{y}=\mathrm{Xb}+\mathrm{Z}_{1} \mathrm{a}+\mathrm{Z}_{2} \mathrm{c}_{\text {ewe }}+\mathrm{e}$

$\mathrm{y}=\mathrm{Xb}+\mathrm{Z}_{1} \mathrm{a}+\mathrm{Z}_{3} \mathrm{c}_{\mathrm{ssire}}+\mathrm{e}$ 
$\mathrm{y}=\mathrm{Xb}+\mathrm{Z}_{1} \mathrm{a}+\mathrm{Z}_{2} \mathrm{c}_{\mathrm{ewe}}+\mathrm{Z}_{3} \mathrm{c}_{\mathrm{ssire}}+\mathrm{e}$

In these models, $\mathrm{y}$ was a vector of observations for growth traits, survival and ewe reproduction traits, $\mathrm{b}, \mathrm{a}, \mathrm{c}_{\mathrm{pe}}, \mathrm{c}_{\mathrm{ewe}}, \mathrm{c}_{\mathrm{ssire}}$ and $\mathrm{c}_{\mathrm{te}}$ were vectors of fixed effects, direct genetic effects, permanent environmental effects due to the dam, ewe and service sire, and temporary environmental effects due to the dam, respectively. $X, Z_{1}, Z_{2}, Z_{3}$ and $Z_{4}$ were the corresponding incidence matrices relating the respective effects to $\mathrm{y}$ and e the vector of residuals. It was assumed that: $\mathrm{V}(\mathrm{a})=\mathrm{A} \sigma_{\mathrm{a}}^{2} ; \mathrm{V}\left(\mathrm{c}_{\mathrm{pe}}\right)=\mathrm{I} \sigma_{\text {pe }}^{2} ; \mathrm{V}\left(\mathrm{c}_{\mathrm{ewe}}\right)=\mathrm{I} \sigma^{2}{ }_{\text {ewe }} ; \mathrm{V}\left(\mathrm{c}_{\mathrm{ssire}}\right)=$ $\mathrm{I} \sigma_{\text {ssire }}^{2} \mathrm{~V}\left(\mathrm{c}_{\mathrm{te}}\right)=\mathrm{I} \sigma_{\text {te }}^{2} ; \mathrm{V}(\mathrm{e})=\mathrm{I} \sigma_{\mathrm{e}}^{2}$, with A being the numerator relationship matrix, I an identity matrix; $\sigma_{\mathrm{a}}^{2}$,

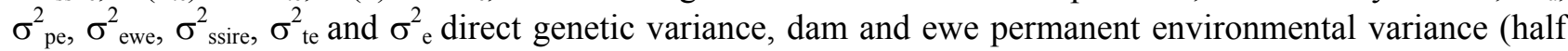
sibs across years), service sire permanent environmental variance, temporary environmental variance (full sibs within year) and environmental (residual) variance respectively. All analyses included the full pedigree consisting of 11954 records. Subsequently, bivariate animal models were fitted which allowed the calculation of relevant correlations between traits, together with their appropriate standard errors.

Lamb survival (whether a lamb survived to weaning or not) was considered a trait of the lamb. Survival was analysed by fitting a univariate model with a logit link function to link the binomially distributed data to the normal distribution. Non-genetic factors included in the model were sex, birth status, age of dam, year of birth and birth weight as a co-variable. Survival was defined as a zero if the lamb was not alive at weaning and one if alive at weaning.

\section{Results and Discussion}

Model selection regarding the random part was done according to log likelihoods. Log likelihoods obtained for each trait under the different models of analyses with the most appropriate model in bold, are given in Tables 2 and 3. The most appropriate model for birth weight included direct additive and maternal effects, the genetic covariance between direct and maternal effects as well as permanent environmental effect and temporary environmental effect (litter) (Model 12). The appropriate model for weaning weight was similar except for the exclusion of the covariance between animal effects. The model with temporary environmental effect as the only additional component to the direct effect was found to be superior for survival. The model with the direct additive and permanent environmental effect due to the dam (ewe) was the most appropriate for total number of lambs born and weaned per parity and, total birth (uncorrected) and weaning weight per parity. The superiority of models containing a temporary environmental effect (lamb traits) indicates a common environmental or non-additive genetic resemblance among littermates.

Table 2 Log likelihoods obtained for pre-weaning growth traits and survival under 12 different models with the 'best' model in bold

\begin{tabular}{|c|c|c|c|c|c|}
\hline Model & (Co)Variance components & BW & WW & \multicolumn{2}{|c|}{ Survival } \\
\hline & & & & $\begin{array}{c}\text { BW } \\
\text { included }\end{array}$ & BW excluded \\
\hline 0 & Fixed effects & -1974.07 & -19962.1 & -17465.4 & -17216.0 \\
\hline 1 & $\mathrm{~h}^{2}$ & -1534.95 & -19822.0 & -16999.1 & -16820.5 \\
\hline 2 & $\mathrm{~h}^{2}+\mathrm{m}^{2}$ & -1058.46 & -19703.5 & -16928.4 & -16759.1 \\
\hline 3 & $\mathrm{~h}^{2}+\mathrm{m}^{2}+\mathrm{r}_{\mathrm{am}}$ & -1052.07 & -19702.1 & - & - \\
\hline 4 & $\mathrm{~h}^{2}+\mathrm{c}_{\mathrm{pe}}^{2}$ & -1092.94 & -19705.1 & -16739.2 & -16595.1 \\
\hline 5 & $h^{2}+m^{2}+c_{p e}^{2}$ & -1024.25 & -19683.4 & -16739.8 & -16596.4 \\
\hline 6 & $h^{2}+m^{2}+c_{p e}^{2}+r_{a m}$ & -1019.81 & -19682.1 & - & - \\
\hline 7 & $\mathrm{~h}^{2}+\mathrm{c}_{\text {te }}^{2}$ & -1041.37 & -19698.4 & -16504.2 & -16360.1 \\
\hline 8 & $\mathrm{~h}^{2}+\mathrm{m}^{2}+\mathrm{c}_{\mathrm{te}}^{2}$ & -757.44 & -19623.9 & -16504.2 & -16360.0 \\
\hline 9 & $\mathrm{~h}^{2}+\mathrm{m}^{2}+\mathrm{c}_{\mathrm{te}}^{2}+\mathrm{r}_{\mathrm{am}}$ & -753.61 & -19622.6 & - & - \\
\hline 10 & $\mathrm{~h}^{2}+\mathrm{c}_{\mathrm{pe}}^{2}+\mathrm{c}^{2} \mathrm{te}_{\mathrm{e}}$ & -805.78 & -19636.5 & -16520.3 & -16374.1 \\
\hline 11 & $\mathrm{~h}^{2}+\mathrm{m}^{2}+\mathrm{c}_{\mathrm{pe}}^{2}+\mathrm{c}_{\mathrm{te}}^{2}$ & -739.19 & -19614.7 & -16521.0 & -16375.2 \\
\hline 12 & $\mathrm{~h}^{2}+\mathrm{m}^{2}+\mathrm{c}_{\mathrm{pe}}^{2 \mathrm{pu}}+\mathrm{c}_{\mathrm{te}}^{2}+\mathrm{r}_{\mathrm{am}}$ & -732.65 & -19613.5 & - & - \\
\hline
\end{tabular}

$\mathrm{Chi}^{2}$ for $\alpha=0.05$ and $1 \mathrm{df}=3.841(\mathrm{Co})$ variance ratios: $\mathrm{h}^{2}=$ direct additive; $\mathrm{m}^{2}=$ maternal additive; $\mathrm{c}^{2}$ pe $=$ permanent environmental due to the dam; $\mathrm{c}^{2}{ }_{\text {te }}=$ temporary environmental due to litter; $r_{a m}=$ genetic correlation between animal effects; BW = birth weight; WW = weaning weight 
From a biological point of view it seemed sensible to pre-adjust birth and weaning weights for sex and year of birth before total weight of lamb born and weaned for a specific parity in individual ewes were calculated. It is, however, evident from Table 3 that pre-adjustments for sex and birth year of weaning weight resulted in the same models being chosen. A similar result was obtained by Cloete et al. (2003a). According to log likelihoods for total birth weight the effect of service sire should be included in the model for corrected data. Although the inclusion or exclusion of the effect of service sire was marginal in both cases results with the effect included are shown for the benefit of the reader. The effect of service sire as a proportion of phenotypic variance amounts to only 0.6 and 0.7 percent respectively.

Table 3 Log likelihood ratios for reproduction traits in Dormer ewes under four different random effect models with the "best" model in bold

\begin{tabular}{|c|c|c|c|c|c|c|}
\hline \multirow[t]{2}{*}{ Effects included } & \multicolumn{2}{|c|}{ Number of lambs } & \multicolumn{2}{|c|}{ Total birth weight } & \multicolumn{2}{|c|}{ Total weaning weight } \\
\hline & Born & Weaned & Uncorrected & Corrected $^{\#}$ & Uncorrected & Corrected $^{\#}$ \\
\hline Fixed effects & 980.3 & -262.5 & -8947.5 & -10022.9 & -25876.5 & -26021.9 \\
\hline$h^{2}$ & 1058.6 & -231.5 & -8798.2 & -9897.5 & -25829.6 & -25982.0 \\
\hline $\mathrm{h}^{2}+\mathrm{c}^{2}$ ewe & 1072.3 & -219.1 & -8790.1 & -9889.1 & -25819.1 & -25968.5 \\
\hline$h^{2}+c^{2}$ ssire & 1059.9 & -231.0 & -8796.5 & -9895.3 & -25829.0 & -25981.2 \\
\hline $\mathrm{h}^{2}+\mathrm{c}_{\text {ewe }}^{2}+\mathrm{c}_{\text {ssire }}^{2}$ & 1073.6 & -218.6 & -8788.3 & -9886.9 & -25818.4 & -25967.7 \\
\hline
\end{tabular}

\# Total weight of lamb born and weaned per ewe per year corrected for sex and year of lambing

$\mathrm{c}^{2}{ }_{\text {ewe }}, \mathrm{c}^{2}{ }_{\text {ssire }}=$ permanent environmental effect due to the ewe and service sire

Parameter estimates fitting most appropriate models for production traits and survival (lamb traits) are presented in Table 4. In the case of birth weight, genetic parameters obtained from a wide range of sheep breeds ranged from 0.07 to 0.23 for $\mathrm{h}^{2}, 0.07$ to 0.30 for $\mathrm{m}^{2}$ and from 0.08 to 0.25 for $^{2}{ }_{\mathrm{pe}}$ (Matika et al., 2003). Estimates of the present study of 0.13 for $\mathrm{h}^{2}, 0.22$ for $\mathrm{m}^{2}$ and 0.09 for $\mathrm{c}^{2}$ pe generally accords well with the range of literature values cited above. Corresponding estimates for weaning weight were 0.07, 0.08 and 0.07 respectively, which are in accordance with those of Boujenane \& Kansari (2002) and are within the range of other literature values (0.06 to 0.39) (Cloete et al., 2001; Matika et al., 2003).

Permanent environmental variance $\left(\sigma_{\mathrm{pe}}^{2}\right)$ accounted for $7 \%$ of the phenotypic variation in weaning weight. Literature estimates, using different models and breeds, indicated that $\sigma_{\mathrm{pe}}^{2}$ accounted for 8 to $19 \%$ of the total phenotypic variance in weaning weight (Matika et al., 2003). The estimate of the current study is lower than some literature estimates and can be attributed to the inclusion of $\mathrm{c}^{2}$ te in the model.

The temporary environmental effect (full sib within year) $\left(\mathrm{c}_{\mathrm{te}}^{2}\right)$, dominates pre-weaning performance. For birth and weaning weight, $\mathrm{c}^{2}$ te accounted for 28 and $22 \%$ of the total phenotypic variation, respectively. Comparing models 6 and 12 (birth weight) and 5 and 11 (weaning weight) showed marked reductions in error variance $\left(\sigma_{\mathrm{e}}^{2}\right)$ and permanent environmental $\left(\sigma_{\mathrm{pe}}^{2}\right)$ variance when $\mathrm{c}^{2}{ }_{\text {te }}$ was fitted. These reductions in, especially, $\sigma_{\mathrm{e}}^{2}$ were significant and amounts to $41 \%$ and $25 \%$ respectively for birth and weaning weight (not presented), indicating that some of the temporary environmental variance has been attributed to $\sigma_{\mathrm{e}}^{2}$ and some to $\sigma_{p e}^{2}$ when $c^{2}{ }_{t e}$ was not fitted. Similar general patterns were reported by Maniatis \& Pollot (2002) for 8week weight in Suffolk sheep and Saatci et al., (1999) for 12-week weight in Welsh mountain sheep. According to Al-Shorepy \& Notter (1998) these effects include not only common environmental effects unique to the litter but also non-additive genetic effects expressed in full-sibs and genotype $\mathrm{x}$ year interaction effects expressed in the dam. Not considering these effects in breeding value predictions of lamb traits may result in inappropriate weighting of the contribution from multiple births.

There is conflicting evidence in the literature on the magnitude and direction of the genetic correlation $\left(\mathrm{r}_{\mathrm{am}}\right)$ between direct and maternal animal effects. This correlation is of major concern in animal breeding. According to Maniatis \& Pollot (2002) these correlations could be negative for reasons other than the existence of a true antagonistic biological relationship between direct and maternal genetic effects. It could be the result of the structure of the data available (Lewis \& Beatson, 1999). However, negative estimates of the direct-maternal correlations are a common feature of most recent analysis of field data. In Romanov sheep it varied between -0.99 and 0.99 (Maria et al., 1993). In the present study the genetic correlation between direct and maternal effects $\left(\mathrm{r}_{\mathrm{am}}\right)$ was -0.23 for birth weight. The estimate was intermediate compared to other literature values $(-0.63$ to +0.52$)$ when fitting the same model without temporary environment (Matika et al., 2003). The estimate is lower than that of -0.35 found by Van Wyk et al. (1993b) also on the 
Dormer, using part of the same data set. The difference in $r_{a m}$ between the two studies can in part be explained by the fact that maternal permanent and temporary environmental effects were not considered in the previous study by Van Wyk et al. (1993b).

Heritability estimates for lamb survival reported in literature are generally very low. The estimate obtained in the present study (0.02), although non significant (i.e. at a level of two times the corresponding standard error), accords well with literature values which vary between 0.00 and 0.09 (Olivier et al., 1998; Snyman et al., 1998; Cloete et al., 2001; Matika et al., 2003). Lamb survival is a complex trait influenced by the lamb's own ability to survive and by its dam's rearing ability (Burfening, 1993). The temporary environmental (litter) effect was found to be more important in affecting survival of the lamb than the direct genetic and permanent environmental components. This implies that more attention to differential management of lambs from different birth types is necessary. The inclusion of birth weight as a covariate, in this case, had virtually no effect on the estimates. This result might be attributed to the data set since stillborn lambs were weighed after birth and were not omitted from the data set. Estimates (literature and present study) indicated that the selection response for increased lamb survival rate will be limited, although some genetic variation appears to exist. According to Cloete et al. (2001) successes with regard to genetic gains in lamb survival and/or ewe rearing ability were reported in the literature.

Table 4 Variance components and ratios ( \pm s.e.) for production traits and survival

\begin{tabular}{|c|c|c|c|c|}
\hline & \multicolumn{2}{|c|}{ Weight } & \multicolumn{2}{|c|}{ Survival } \\
\hline & Birth & Weaning & BW included & BW excluded \\
\hline \multicolumn{5}{|l|}{ Variance components } \\
\hline Total phenotypic $\left(\sigma_{p}^{2}\right)$ & 0.553 & 22.22 & 3.729 & 3.741 \\
\hline Residual $\left(\sigma_{e}^{2}\right)$ & 0.174 & 12.47 & 1 & 1 \\
\hline Direct additive $\left(\sigma_{\mathrm{a}}^{2}\right)$ & 0.074 & 1.58 & 0.063 & 0.062 \\
\hline Maternal additive $\left(\sigma_{\mathrm{m}}^{2}\right)$ & 0.123 & 1.81 & - & - \\
\hline Covariance $\left(\sigma_{\mathrm{am}}\right)$ & -0.022 & - & - & - \\
\hline Permanent environment $\left(\sigma_{\mathrm{pe}}^{2}\right)$ & 0.047 & 1.470 & - & - \\
\hline Temporary environment $\left(\sigma_{\text {te }}^{2}\right)$ & 0.155 & 4.89 & 0.376 & 0.389 \\
\hline \multicolumn{5}{|l|}{ Variance ratios } \\
\hline Direct additive $\left(\mathrm{h}^{2}\right)$ & $0.133(0.025)$ & $0.071(0.018)$ & $0.017(0.015)$ & $0.017(0.014)$ \\
\hline Maternal additive $\left(\mathrm{m}^{2}\right)$ & $0.227(0.029)$ & $0.081(0.018)$ & - & - \\
\hline Permanent environment $\left(\mathrm{c}_{\mathrm{pe}}^{2}\right)$ & $0.085(0.016)$ & $0.066(0.014)$ & - & - \\
\hline Temporary environment $\left(\mathrm{c}_{\mathrm{te}}^{2}\right)$ & $0.281(0.013)$ & $0.220(0.018)$ & $0.101(0.015)$ & $0.104(0.019)$ \\
\hline $\begin{array}{l}\text { Genetic correlation between animal } \\
\text { effects }\left(\mathrm{r}_{\mathrm{am}}\right)\end{array}$ & $-0.233(0.098)$ & - & - & - \\
\hline
\end{tabular}

Parameter estimates fitting most appropriate models for reproduction traits (ewe traits) are presented in Table 5. The estimates obtained for number of lambs born and weaned were generally low. The $\mathrm{h}^{2}$ estimate for number of lambs born per ewe lambing (0.06) presented in Table 5 falls within the range of literature estimates $(0.03$ - 0.12) (Brash et al., 1994b; Bromley et al., 2000; Rosati et al., 2002; Cloete et al., 2002a; b; 2003). In the case of number of lambs weaned per ewe lambing, the estimate was 0.03 . Comparable estimates in the literature ranged from 0.00 to 0.10 (Brash et al., 1994b, Bromley et al., 2000, Swan et al., 2001; Cloete et al., 2002a; b; Rosati et al., 2002; Cloete et al., 2003; Matika et al., 2003). The fraction of variance due to permanent environment was 0.07 for both traits which corresponds well with estimates obtained by Bromley et al. (2000); Swan et al. (2001) and Rosati et al. (2002)

Total weaning weight per ewe lambing is a trait often used as an overall measure of lamb production (Bromley et al., 2001) and has had favourable genetic and economic responses (Ercanbrack \& Knight, 1998). Total weaning weight, a composite trait, depends on fertility, litter size, weight (growth) of individual lambs, mothering ability and embryonic and lamb survival. The net reproduction of a ewe can thus be defined in terms of total weight of lamb weaned per ewe per parity (Olivier, 1999). For four sheep breeds, Bromley et al. (2001) reported direct heritability estimates of total weaning weight, ranging from 0.02 to 0.11 fitting the same model as in the present study, while Snyman et al. (1997) reported values ranging from 0.05 to 0.26 for 
Afrino and Merino sheep. Although on the lower side, the current estimate for total weaning weight (0.04) falls within the range of literature values (Cloete et al., 2002a; b; 2003; Matika et al., 2003).

Table 5 Variance components and ratios (SE) of reproduction traits (considered as traits of the ewe).

\begin{tabular}{lcccccc}
\hline Trait & \multicolumn{2}{c}{ Total birth weight } & \multicolumn{2}{c}{ Total weaning weight } & NLB & NLW \\
& Uncorrected & ${ }^{\#}$ Corrected & Uncorrected & ${ }^{\#}$ Corrected & & \\
\hline Residual $\left(\sigma^{2}{ }_{\mathrm{e}}\right)$ & 2.898 & 3.873 & 236.411 & 245.734 & 0.24 & 0.341 \\
Total phenotypic $\left(\sigma^{2}{ }_{\mathrm{p}}\right)$ & 3.566 & 4.689 & 267.6 & 277 & 0.2767 & 0.3785 \\
Direct additive $\left(\sigma^{2}{ }_{\mathrm{a}}\right)$ & 0.436 & 0.503 & 13.305 & 10.644 & 0.016 & 0.010 \\
Permanent environment & 0.212 & 0.283 & 17.856 & 20.58 & 0.021 & 0.027 \\
$\left(\sigma^{2}{ }_{\text {ewe }}\right)$ & & & & & \\
Service sire $\left(\sigma^{2}{ }_{\text {ssire }}\right)$ & 0.020 & 0.032 & - & - & - & - \\
$\mathrm{h}^{2}{ }_{\text {animal }}$ & 0.122 & 0.107 & 0.050 & 0.038 & 0.059 & 0.026 \\
$\mathrm{SE}$ & $(0.020)$ & $(0.019)$ & $(0.015)$ & $(0.013)$ & $(0.015)$ & $0.012)$ \\
$\mathrm{c}^{2}{ }_{\text {ewe }}$ & 0.059 & 0.060 & 0.067 & 0.074 & 0.075 & 0.073 \\
$\mathrm{SE}$ & $(0.015)$ & $(0.015)$ & $(0.015)$ & $(0.014)$ & $(0.015)$ & $(0.014)$ \\
$\mathrm{c}^{2}{ }_{\text {ssire }}$ & 0.006 & 0.007 & - & - & - & - \\
$\mathrm{SE}$ & $(0.003)$ & $(0.004)$ & & & & \\
Repeatability & 0.182 & 0.168 & 0.117 & 0.113 & 0.133 & 0.098 \\
$\mathrm{SE}$ & $(0.014)$ & $(0.014)$ & $(0.013)$ & $(0.013)$ & $(0.013)$ & $(0.012)$ \\
\hline
\end{tabular}

\# Total weight of lamb weaned per ewe per parity corrected for sex and year of lambing

$\mathrm{NLB} ; \mathrm{NLW}=$ total number of lambs born and weaned per parity

Estimates from other studies (Duguma et al., 2002; Rosati et al., 2002; Matika et al., 2003) are higher than the estimate in this study. The distribution of data for total weaning weight in the current study is highly skewed due to the inclusion of a large number of zero values for those ewes which failed to wean a lamb. This might have contributed to lower estimates. Estimates of $\mathrm{c}^{2}{ }_{\mathrm{pe}}$ for reproduction traits accord to estimates reported by Bromley et al. (2000) (0.01 to 0.07)

The genetic correlation estimate between birth and weaning weight (0.36) (Table 6) accords to the weighted average of 0.39 (Fogarty, 1995) but is higher than the estimate of Neser et al. (2001) in Dorper sheep. These results indicate that it is possible to genetically improve weaning weight without significant increases in birth weight.

The correlations between multiple records of the same animal (repeatability) were low for all reproduction traits ranging from 0.18 for total birth weight to 0.10 for number of lambs weaned. This indicates that reproduction of the ewe in her first or second parity is not a good indicator of her future performance. These values are in good agreement with those of Bromley et al. (2001) and Cloete et al. (2003b). The low repeatability (0.11), however, contradicts the recommendation of Snyman et al. (1997) that first record of total weaning weight can be used as a basis to improve lifetime reproduction of the ewe. Repeatability estimates are generally useful in prediction of producing ability (current flock) in order to properly weight the contributions of repeated records (Bourdon, 2000).

Genetic correlations of total weight of lamb weaned with the other reproduction traits were generally high with low standard errors. The corresponding phenotypic, environmental and ewe permanent environmental correlations were all medium to high and estimated with a fair deal of accuracy according to low standard errors. The relationship between weaning weight of the ewe and her lifetime reproduction was somewhat lower and not significant as far as environmental correlations are concerned. These results suggest that selection on direct breeding values for increased weaning weight will not detrimentally affect reproduction. Although live weights at joining or at hogget age are genetically positively related to total weight of lamb weaned in Merinos (Cloete et al., 2002; 3003b), it has not been studied in dual-purpose or meat sheep. In the previous study of Van der Merwe (1976) on the Elsenburg Dormer stud, reproduction was not phenotypically related to live weight. So far, the genetic correlation between weaning weight and reproduction has only been studied in Merinos (Olivier et al., 2001). It is important to note that the present study yielded similar results in a meat breed. Correlations between number of lambs weaned per ewe and weight of lamb weaned per ewe were particularly high $(0.8-0.9)$. All correlations between uncorrected and 
corrected weight of lamb weaned per ewe were either unity, or not significantly different from it as was also observed by Cloete et al. (2003).

Table 6 Genetic, ewe permanent environmental (PE), phenotypic and environmental correlations (SE) among production and reproduction traits

\begin{tabular}{lcccc}
\hline Traits & Genetic & Ewe PE & Phenotypic & Environmental \\
\hline Birth x weaning weight & $0.36(0.13)$ & $0.75(0.11)$ & $0.37(0.01)$ & $0.38(0.02)$ \\
& & & & \\
Total weight of lamb weaned $\mathbf{x}$ & & & & \\
Total weight of lamb weaned (TWW) & $0.998(0.00)$ & $0.998(0.00)$ & $0.98(0.00)$ & $0.98(0.00)$ \\
Number of lambs born (TLB) & $0.64(0.14)$ & $0.64(0.09)$ & $0.47(0.01)$ & $0.45(0.01)$ \\
Number of lambs weaned (TLW) & $0.81(0.09)$ & $0.92(0.02)$ & $0.93(0.00)$ & $0.93(0.00)$ \\
& & & & \\
Total weight of lamb weaned ${ }^{*} \mathbf{x}$ & $0.69(0.12)$ & $0.62(0.10)$ & $0.48(0.01)$ & $0.45(0.01)$ \\
Number of lambs born & $0.86(0.06)$ & $0.91(0.02)$ & $0.92(0.00)$ & $0.92(0.00)$ \\
Number of lambs weaned & & & & \\
Number of lambs born $\mathbf{x}$ & $0.96(0.14)$ & $0.88(0.06)$ & $0.61(0.01)$ & $0.58(0.01)$ \\
Number of lambs weaned & & & & \\
Weaning weight of ewe $\mathbf{x}$ & & - & $0.14(0.02)$ & $0.004(0.03)$ \\
TWW4 & $0.67(0.12)$ & - & $0.13(0.02)$ & $0.07(0.03)$ \\
TLB4 & $0.40(0.14)$ & - & $0.13(0.02)$ & $0.05(0.03)$ \\
TLW4 & $0.41(0.14)$ & - & \\
\hline
\end{tabular}

${ }^{\#}$ Total weight of lamb weaned per ewe per year corrected for sex and year of lambing

TWW4, TLB4 and TLW4 were calculated as accumulated totals only for ewes which had four consecutive lambing opportunities

\section{Conclusions}

The results of this study confirm the importance of implementing the correct model regarding random effects for the estimation of genetic parameters. Exclusion of important components in genetic analyses obviously has the effect of inflating the remaining parameter estimates. It was clearly shown that the maternal environmental effect should be partitioned into two components (permanent and temporary) when data sets involving multiple births over many generations are considered. Ignoring these effects in breeding value predictions of birth and weaning weight might result in inappropriate weighting of the contribution from multiple births.

Total weight of lamb weaned should be considered in the selection strategy since it is a composite trait incorporating elements of not only lamb growth and survival to weaning, but also ewe reproductive performance. Genetic correlation between weaning weight of the ewe and her lifetime reproduction (four lambing chances) of $0.4-0.7$ indicates that the reproduction performance of the ewe will not be adversely influenced by selection for weaning weight.

\section{Acknowledgements}

The authors wish to thank the Director, ARC - Animal Improvement Institute and the Elsenburg Agricultural Development Institute, for kind permission to use the data.

\section{References}

Al-Shorepy, S.A. \& Notter, D.R., 1998. Genetic parameters for lamb birth weight in spring and autumn lambing. Anim. Sci. 67, 327-332.

Boujenane, I. \& Kansari, J., 2002. Estimates of (co)variances due to direct and maternal effects for body weights in Timahdite sheep. Anim. Sci. 74, 409-414.

Bourdon, R.M., 2000. Understanding animal breeding. $2^{\text {nd }}$ edition. Prentice-Hall Inc., New Jersey.

Bromley, C.M., Snowder, G.D., Van Vleck, L.D., 2000. Genetic parameters among weight, prolificacy, and wool traits of Columbia, Polypay, Rambouillet, and Targhee sheep. J. Anim. Sci. 78, 846-858. 
Bromley, C.M., Van Vleck, L.D. \& Snowder, G.D., 2001. Genetic correlations for litter weight weaned with growth, prolificacy and wool traits in Columbia, Polypay, Rambouillet and Targhee sheep. J. Anim. Sci. 79, 339-346.

Burfening, P.J., 1993. Direct and maternal genetic effects on lamb survival. Small Rumin. Res. 11, 267 - 274.

Cloete, S.W.P., Gilmour, A.R., Olivier, J.J. \& Van Wyk, J.B., 2003a. Age trends in economically important traits of Merino ewes subjected to 10 years of divergent selection for multiple rearing ability. S. Afr J. Anim. Sci. 33, 43-51

Cloete, S.W.P., Gilmour, A.R., Olivier, J.J. \& van Wyk, J.B., 2003b. Genetic parameters and trends in Merino lines divergently selected for multiple rearing ability. Proc. Assoc. Advmnt Anim. Breed. Genet. 15, 253-256.

Cloete, S.W.P., Greeff, J.C. \& Lewer, R.P., 2001. Environmental and genetic aspects of survival and early body weight in Western Australian Merino sheep. S. Afr. J. Anim. Sci. 31, 123-130.

Cloete, S.W.P., Greeff, J.C. \& Lewer, R.P., 2002a. Heritability estimates and genetic and phenotypic correlations of lamb production parameters with hogget liveweight and fleece traits in Western Australian Merino sheep. Aust. J. Agric. Res. 53, 281-286.

Cloete, S.W.P., Greeff, J.C. \& Lewer, R.P., 2002b. Genetic and environmental variances in lamb production traits of Merino ewes in a Meditarranean environment. Wool Tech. Sheep Breed. 50, 395-400.

Duguma, G.J., Schoeman, S.J., Cloete, S.W.P. \& Jordaan, G.F., 2002. Genetic parameter estimates of early growth traits in the Tygerhoek Merino flock. S. Afr. J. Anim. Sci. 32, 66-75.

Ercanbrack, S.K. \& Knight, A.D., 1998. Responses to various selection protocols for lamb production in Rambioullet, Targhee, Columbia and Polypay sheep. J. Anim. Sci. 76, 1311-1325.

Fogarty, N.M., 1995. Genetic parameters for live weight, fat and muscle measurements, wool production and reproduction in sheep: a review. Anim. Breed. Abstr. 63, 101-143.

Gilmour, A.R., Gogel, B.J., Cullis, B.R., Welham, S.J. \& Thompson, R., 2002. ASREML- User Guide Release 1.0 VSN International Ltd, Hemel Hempstead, HP1 1ES, UK.

Johnson, D.L. \& Garrick, D.J., 1990. Data collection, processing and prediction of breeding values. Proc. $4^{\text {th }}$ World Congr. Gen. Appl. Livest. Prod. XV, 337-346.

Lewis, R.M. \& Beatson, P.R., 1999. Choosing maternal-effect models to estimate (co)variances for live and fleece weight in New Zealand Coopworth sheep. Livest. Prod. Sci. 58, 137-150.

Maniatis, N. \& Pollot, G.E., 2002. Genotype by environment interactions in lamb weight and carcass composition traits. Anim. Sci. 75, 3-14.

Maria, G.A., Boldman, K.G. \& Van Vleck, L.D., 1993. Estimates of variances due to direct and maternal effects for growth traits of Romanov sheep. J. Anim. Sci. 71, 845-849.

Matika, O., Van Wyk, J.B., Erasmus, G.J. \& Baker, R.L., 2003. Genetic parameter estimates in Sabi sheep. Livest. Prod. Sci. 79, 17-28.

Neser, F.W.C., Erasmus, G.J. \& Van Wyk, J.B., 2001. Genetic parameter estimates for pre-weaning weight traits in Dorper sheep. Small Rumin. Res. 40, 197-202.

Olivier, J.J., 1999. The South African Merino performance testing scheme. In: Rising to the challenge Breeding for the $21^{\text {st }}$ Century Customer. Beef Industry and CRC for Premium Quality Wool Industry Symposia. Proc. Assoc. Advmnt Anim. Breed. Genet. 13, 119-124.

Olivier, W.J., Snyman, M.A., Van Wyk, J.B. \& Erasmus, G.J., 1998. Genetic parameter estimates for fitness traits in South African Merino. Livest. Prod. Sci. 56, 71-77.

Olivier, W.J., Snyman, M.A., Olivier, J.J., Van Wyk, J.B. \& Erasmus, G.J., 2001. Direct and correlated responses to selection for total weight of lamb weaned in Merino sheep. S. Afr. J. Anim. Sci. 31, 115-121.

Rosati, A., Mousa E., Van Vleck, L.D. \& Young, L.D., 2002. Genetic parameters of reproductive traits in sheep. Small Rumin. Res. 43, 65-74.

Saatci, M., Ap Dewi, I. \& Ulutas, Z., 1999. Variance components due to direct and maternal effects and estimation of breeding values for 12-week weight of Welsh Mountain lambs. Anim. Sci. 69, 345352.

SAS, 1991. Statistical Analysis Systems users' guide. (6.03 ed.), SAS Institute Inc., Cary, North Carolina, USA.

Snyman, M.A., Olivier, J.J., Erasmus, G.J. \& Van Wyk, J.B., 1997. Genetic parameter estimates for total weight of lamb weaned in Afrino and Merino sheep. Livest. Prod. Sci. 48, 111-116. 
Snyman, M.A., Erasmus, G.J. \& Van Wyk, J.B., 1998. The possible genetic improvement of reproduction and survival rate in Afrino sheep using a threshold model. S. Afr. J. Anim. Sci. 28, 120-124.

Van der Merwe, C.A., 1976. Genetiese en nie-genetiese faktore wat die produksie- en reproduksie eienskappe van die Elsenburgse Dormerskaapkudde beïnvloed. PhD thesis, University of Stellenbosch, Stellenbosch, South Africa.

Van Wyk, J.B., Erasmus, G.J. \& Konstantinov, K.V., 1993a. Non-genetic factors influencing early growth traits in the Elsenburg Dormer sheep stud. S. Afr. J. Anim. Sci. 23, 67-71.

Van Wyk, J.B., Erasmus, G.J. \& Konstantinov, K.V., 1993b. Variance component and heritability estimates of early growth traits in the Elsenburg Dormer sheep stud. S. Afr. J. Anim. Sci. 23, 72-76.

Van Wyk, J.B., Erasmus, G.J. \& Konstantinov, K.V., 1993c. Inbreeding in the Elsenburg Dormer sheep stud. S. Afr. J. Anim. Sci. 23, 77-80.

Van Wyk, J.B., Erasmus, G.J., Konstantinov, K.V. \& Van Der Westhuizen, J., 1993d. Relationships between early growth traits in the Elsenburg Dormer sheep stud. S. Afr. J. Anim. Sci. 23, 81-84.

Van Wyk, J.B., Erasmus, G.J. \& Konstantinov, K.V., 1993e. Genetic and environmental trends in the Elsenburg Dormer stud. S. Afr. J. Anim. Sci. 23, 85-87.

Van Wyk, J.B., Fair, M.D. \& Erasmus, G.J., 2002. An update of inbreeding in the Elsenburg Dormer stud. Proc. GSSA/SASAS Jnt Congr., 13 - 16 May, Christiana. pp. 29. 